
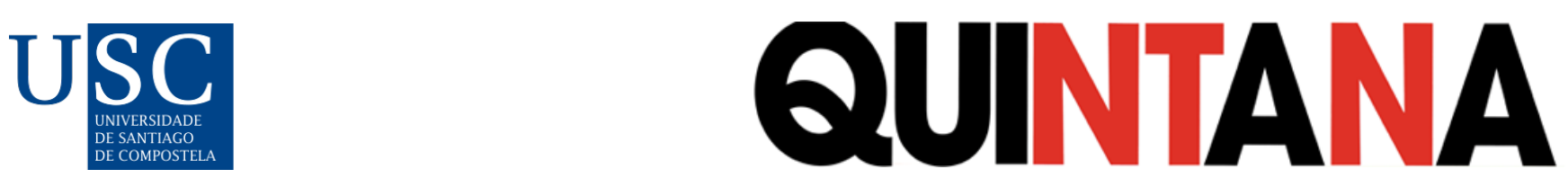

Quintana: revista do Departamento de Historia da Arte, (20), 2021. ISSN-e: 2340-0005

https://doi.org/10.15304/quintana.20.7675

Reseñas

\title{
La conferencia de museos de 1934, en perspectiva. Actas congreso internacional de museografía. Alicia Herrero Delavenay y Carmen Sanz Díaz (Ed. y Coord.), Real Academia de Bellas Artes de San Fernando, Madrid, 2018. 358 págs. ISBN 978-84-9640-648-3
}

\author{
Clara Moura Soares ${ }^{1}$ \\ ${ }^{1}$ Universidade de Lisboa, Portugal
}

Mais de oito décadas volvidas sobre a realização da Conferência Internacional de Museografia que teve lugar na Academia Real de Bellas Artes de San Francisco, em Madrid, entre 28 de outubro e 4 de novembro de 1934, realizou-se no mesmo lugar, em 2016, o Congreso Internacional de Museografia - La Conferencia de Museos de 1934, en perspectiva, que pretendeu celebrar o acontecimento que constituiu um marco histórico da maior relevância na museologia e na museografia mundial. Apesar de ter tido algum eco em Portugal nos anos de 1930, através do então diretor do Museu Nacional de Arte Antiga (Lisboa), Dr. José de Figueiredo, que assistiu ao evento acompanhado pelo arquiteto Guilherme Rebelo de Andrade, este apresenta, contudo, escassa expressão na bibliografia portuguesa recente sobre história da museografia e da museologia. É esta uma das razões que justifica o nosso interesse pelo tema da publicação coordenada por Alicia Herrero Delavenay (então conservadora do Museo Nacional de Artes Decorativas, Madrid) e por Carmen Sanz Díaz (então conservadora do Museo Cerralbo, Madrid), objeto desta recensão, a quem se ficou a dever também a organização do congresso de 2016, que esteve na sua base.

Tratou-se de revisitar um evento pioneiro em matéria de museografia, coorganizado pelo International Museums Office (antecessor do ICOM) e pelo governo espanhol, que pôde contar com a participação de 68 profissionais de museus e mais de 200 pessoas na assistência. Resultou na edição de um manual de referência, em 2 volumes, cuja publicação, constituída por dezoito textos, de autores como Louis Hautecoeur (França), Clarence S. Stein (Nova York), Sir Eric Robert Dalrymple McLagan (Reino Unido), Roberto Paribeni (Itália), Federik Schmidt-Degener (Países Baixos), Alfred Stix (Áustria), George Oprescu (Roménia), Joergen Olrik (Dinamarca), Axel Gauffin (Suécia), Ludwig Marton (Hungria), Pedro Muguruza Otanõ (Espanha), é a prova material da importância e pioneirismo da iniciativa de 1934, nomeadamente do seu grau de internacionalização. Nela se abordaram as mais diversas temáticas da museografia e da museologia modernas, entre as quais o funcionalismo da arquitetura, a iluminação, as reservas, a segurança, o inventário, a interdisciplinaridade, a importância do público.

A obra em foco na presente recensão constitui o volume de atas do Congreso Internacional de Museografia - La Conferencia de Museos de 1934, en perspectiva, que decorreu entre 21 e 23 de 
novembro de 2016. Pretendemos, assim, juntar-nos, de alguma forma, às celebrações do evento de 1934, contribuindo para realçar a sua importância. Ao mesmo tempo, prestamos a nossa deferência aos organizadores e participantes na iniciativa que se propôs revisitar aquela conferência e analisar, de forma crítica e dinâmica, os seus efeitos ao longo das décadas que se lhe seguiram, abrindo à reflexão problemáticas de grande atualidade no domínio dos museus.

O volume compõe-se de três partes, num total de vinte e cinco textos da autoria de reconhecidos museólogos, professores, arquitetos, investigadores, a que se acrescentam resumos das três mesas redondas promovidas no âmbito do congresso, sobre os protagonistas da conferência de 1934, a presença do tema dos museus na comunicação social escrita e a evolução da arquitetura museal e da museografia nos séculos XX e XXI, redigidos pelas coordenadoras do evento e editoras das atas, conceituadas especialistas em História da Arte e em Museologia.

A primeira parte do volume, antecedida por notas de abertura do Presidente da Real Academia de Bellas Artes de San Fernando, do Presidente do ICOM Espanha, do delegado do Museu da Real Academia de San Fernando e das organizadoras do evento, é formada por quatro textos. Centramse estes na conjuntura histórica e cultural em que decorreu a conferência do International Museum Office (IMO), questões cuja reflexão permanecia até então, amplamente, em aberto. Através do estudo de François Mainesse, abordam-se, no domínio internacional, os museus e a museologia no período entre guerras mundiais, momento em que se regista um crescimento exponencial do número de instituições museológicas por toda a Europa e que representa uma fase de charneira no seu desenvolvimento conceptual e técnico. Também os contributos do Congrès d'Histoire de l'Art (Paris, 1921) para a discussão em torno da moderna museografia, são salientados por Mainesse, destacando o papel fundamental do historiador da arte Henri Focillon, a quem se ficou a dever a proposta de criação do IMO, em 1926, no âmbito da Sociedade das Nações. A relação entre política e museus, com particular enfoque sob regimes totalitários, nomeadamente na Alemanha, Itália, Espanha e União Soviética, constitui o tema do texto de Maria Dolores Jiménez-Blanco. Movidos por ideologias nacionalistas e colonialistas esses regimes contribuíram para o incremento de tipologias específicas de museu e de coleções. Por seu turno, Alicia Herrero e Carmen Sanz apresentam os resultados da sua investigação em torno da conferência de 1934, nomeadamente sobre o processo da sua preparação, organização e concretização, trazendo importantes novidades. A primeira parte do volume termina com o contributo de Antonio López Veja, que se detém sobre a caracterização do instável contexto político, económico e social de Espanha, na vigência da II República, época em que decorreu a conferência, inicialmente prevista para outubro de 1933 e por duas vezes adiada.

A segunda parte, composta por dez textos, trata da evolução da museografia e da arquitetura museal iniciada nas primeiras décadas do século XX, prolongando-se pela centúria. No percurso evolutivo, assinala-se a crise do museu moderno e a renovação do paradigma museológico, registado a partir dos anos de 1970, com os museus a serem concebidos como equipamentos destinados às massas.

O capítulo abre com o estudo de Alfonso Muñoz Cosme, que funciona como uma sólida reflexão de âmbito internacional agregadora do conjunto de textos que se seguem. 0 confronto com os museus oitocentistas, através das suas características, entre qualidades e fragilidades, foi o ponto de partida de Alfonso Muñoz, facilitando a compreensão das mudanças registadas sob o efeito das marcas pungentes deixadas pela I Guerra Mundial. 0 museu como "máquina de expor", de complexo funcionamento e com uma nova conceção de espaço, ganha terreno no debate internacional no início do século XX, nomeadamente, através de textos de Julien Guadet, Paul Valéry ou Filippo Marinetti, citados pelo autor. É sob esta nova formulação do museu moderno, que suscitou a 
La conferencia de museos de 1934, en perspectiva. Actas congreso internacional de museografía. Alicia Herrero Delavenay y Carmen Sanz Díaz (Ed. y Coord.), Real Academia de Bellas Artes de San Fernando, Madrid, 2018. 358 págs. ISBN 978-84-9640-648-3

reflexão e o avanço de propostas de grandes arquitetos internacionais, como Auguste Perret, Le Corbusier, Van der Rohe ou Clarence Stein, que se realiza a conferência de 1934, em Madrid, e que se estabelecem os seus painéis temáticos. À década de 1930 estaria reservada a primeira grande mudança de paradigma na arquitetura dos museus, com o MoMa e o Guggenheim, em Nova York, a assumirem a rutura com os modelos tradicionais e a despoletarem a expansão europeia da mudança, sobretudo dos museus destinados à arte moderna e contemporânea. Ao mesmo tempo, a adaptação de edifícios históricos a funções museológicas mantém-se no centro do debate, uma vez que constitui a realidade de muitos países europeus (e.g. Itália, Espanha, Portugal), procurando-se conciliar arquiteturas históricas com alguns requisitos de modernidade estabelecidos pelos novos padrões da museografia.

O contributo de Ángeles Layuno Rosas, focado nos eixos da política cultural da II República espanhola, é fundamental para o enquadramento de seis dos oito textos que se seguem. Consagrados a casos de estudo daquele país, são o claro reflexo de que, apesar das circunstâncias adversas, a II República correspondeu a um período de evolução das instituições museológicas, consequência dos conhecimentos técnicos dos arquitetos espanhóis em matéria de museografia. Reconhece-se o impulso dado pela conferência do IMO, sobretudo no que se refere à renovação para fins museológicos de edifícios pré-existentes, no período de 1933-1935, diante da falta de capacidade económica para se edificar de raiz, salientando-se o efeito travão da Guerra Civil Espanhola em todo o processo, a partir de 1936.

No contexto particular de Espanha destaca-se o enfoque dado por Javier Arnaldo ao estudo visionário e premonitório do artista Gabriel García Maroto, publicado em 1927, com o título La nueva España 1930. Resumen de la vida artística española desde 1927. Um ensaio teórico alicerçado na ideia do museu como um instrumento de renovação artística e social, um autêntico centro de aprendizagem, cujo discurso encontrará correspondência em alguns dos temas tratados na conferência de 1934, mas também em diversos projetos museológicos concretizados no âmbito do museu moderno e funcional então desejado para o século XX. É o caso do Museo Ambulante de las Misiones Pedagógicas, estudado por Carmen Fernández-Salguero, cuja existência entre 1931 e 1936 permitiu levar, de forma inovadora, a arte até às populações rurais, através da realização de 178 exposições itinerantes constituídas por cópias de obras pertencentes ao tesouro artístico nacional espanhol.

A mudança no conceito de museu é igualmente abordada por Rocio Álvaro Sánchez a propósito do Museu do Prado, tratando as políticas de público, nomeadamente a regulamentação de entradas e as visitas didáticas, desenvolvidas entre 1901 e 1920, pelos diretores do museu madrileno, José Villegas e Aureliano Beruete y Moret. Javier Mateo de Castro, por sua vez, debruça-se sobre as ações educativas do Museu Pedagógico Nacional durante a sua existência, entre 1882 e 1941 ; e Ariadna Ruiz Gómez trata da abertura do Museu de Artes Decorativas de Madrid à arte asiática e do seu contributo para a renovação do design europeu. A atividade em museus do arquiteto Pedro Muguruza Otaño, na década de 1930, constitui o tema do estudo de Carlota Bustos Juez. Muguruza teve um papel crucial na realização da conferência de 1934, mas destacou-se igualmente como conservador dos museus da Real Academia de San Fernando (1918-1936) e do Museu do Prado (1923-1952), onde dirigiu importantes projetos de restauro, ampliação e renovação museográfica no contexto da musealização de arquiteturas históricas. Embora não tenha projetado novos edifícios para museus, "fue uno de los protagonistas de la disciplina museística española de la primera mitad del siglo XX", segundo Carlota Bustos, e um amplo conhecedor da realidade museográfica europeia. 
Completam a segunda parte do volume mais dois estudos. Tratam-se de abordagens que visam expandir a reflexão além da realidade espanhola, razão pela qual optámos por os referenciar em conjunto. 0 primeiro texto, de Ariadna Ruiz Gómez, dá conta da escassa presença latino-americana, nomeadamente de países como o Brasil, México e Argentina, no Museum International Office, bem como na conferência de Madrid, avançando a autora com alguma argumentação justificativa. Por sua vez, o estudo de Arturo Tomillo Castillo trata do contributo do arquiteto neerlandês Hendrik Petrus Berlage e do seu projeto para o Gemeentemuseum (Museu Municipal) de Haya, inaugurado em 1935, caso de estudo que havia sido abordado por Louis Hautecoeur na conferência do IMO como um modelo de arquitetura museal moderna. Arturo Tomillo destacou, em particular, as atmosferas e as condições de fruição das obras de arte alcançadas por Berlage através dos efeitos da luz zenital, tão apreciada na época.

$\mathrm{Na}$ terceira parte, através de onze textos, propõe-se uma releitura das atas da conferência de 1934 baseada na análise dos contributos históricos, mas também na perspetiva atual, face aos desafios impostos pelo século XXI em matéria de museografia e de arquitetura de museus.

A abertura é feita por Alicia Herrero e Carmen Sanz, com uma caracterização sumária dos conteúdos dos dois volumes da conferência, publicados em 1935 com o título Museográphie. Architecture et aménagement des Musées d'Art. 0 percurso faz-se pelos seus dezoito capítulos, correspondentes ao número de conferências realizadas em 1934, colocando em evidência os seus autores, as funções profissionais desempenhadas e os seus principais contributos. Por seu turno, Jean Hilgersom, em representação do International Committee for Architecture and Museum Techniques (ICAM/ICOM), estabelece a ponte entre a conferência do IMO e o presente, reconhecendo a importância daquele evento para a época, bem como do que chama de "bíblia do mundo dos museus" publicada no seu âmbito. No seu entender, interrogar e planificar surgem hoje como palavras de ordem na procura de respostas adequadas às necessidades de cada museu, tendo em conta as desafiantes funções que lhes são atribuídas, bastante distantes da missão expositiva dominante nos anos de 1930 e seguintes.

Sucede-se um conjunto de textos, em boa medida, ancorados nas grandes linhas temáticas da conferência de 1934, abordados na dupla perspetiva do seu vanguardismo para a época e da sua atualidade no presente. Carlos Baztán Lacasa trata da planificação dos diferentes espaços dos museus, referindo-se às áreas de reserva, às salas de exposição, aos espaços acessíveis ao público, aos serviços. Através de diversos exemplos museológicos americanos e europeus, inaugurados a partir dos anos de 1930/1940, salienta a importância crescente da acessibilidade dos museus a todos, da funcionalidade dos edifícios museológicos, da implementação de soluções arquitetónicas que tenham nas políticas de conservação preventiva uma prioridade, bem como da sua articulação com as cidades onde se encontram implantados. A adaptação de monumentos antigos e de outros edifícios a museus foi o tema tratado por Víctor Cageao Santacruz, recuperando reflexões abordadas pelo arqueólogo e historiador italiano Roberto Paribeni na conferência do IMO. Assumindo a grande atualidade do tema nos dias de hoje, mas também a sua complexidade, o autor elenca vantagens e desvantagens, face às novas construções, manifestando-se mais favorável a estas últimas pela maior facilidade em se alcançar o sucesso em questões técnicas, como a proteção contra incêndios, o controlo das condições-ambiente, o controlo da iluminação ou do vandalismo. Juan Rodríguez Frade detém-se sobre as exposições temporárias e permanentes, destacando neste contexto a vanguarda e a persistência de muitos dos princípios enunciados em 1934. Distingue o âmbito de cada uma, estabelecendo diversas tipologias de exposições temporárias consoante os objetivos pretendidos. Por sua vez, a organização das reservas, tantas vezes descurada no contexto do debate sobre 
La conferencia de museos de 1934, en perspectiva. Actas congreso

museus, constituiu o foco de Gaël de Guichen. Partindo da constatação de que uma grande maioria dos museus do mundo conserva $90 \%$ das suas coleções em reservas, considera fundamental que estas sejam objeto de uma atenção que não lhes tem sido devida. A conferência do IMO representa a este respeito, segundo o conceituado especialista do ICCROM, "o momento em que tudo começou", fazendo pressupor um futuro promissor que só muito recentemente chegaria. Com grandes hiatos temporais, são apontadas algumas iniciativas importantes, avulsas, que representam uma mudança lenta no entendimento das reservas, como o Congresso do ICOM, Washington, 1976; o Plano Delta, Países Baixos, 1988; e o Programa PREMA - ICRROM,1990-2000. De espaços inacessíveis ao público e onde se recolhem os objetos menos qualificados para serem expostos, as reservas passam, paulatinamente, a ser encaradas como lugares onde as peças que não estão expostas são mantidas em segurança, organizadas e conservadas, prontas para serem expostas a qualquer momento. 0 projeto RE-ORG (Um Método para Reorganizar a Reserva Técnica de Museus), lançado em 2011 por iniciativa do ICCROM, e a sua expansão nos anos subsequentes por diversos países do mundo testemunha o estatuto que começa a ser alcançado pelas reservas no contexto museológico.

Segue-se um conjunto de textos que se debruçam sobre as especificidades de determinadas coleções, que haviam merecido destaque na conferência do $\mathrm{IMO}^{1}$, organizados conforme o volume II da obra Museográphie e, no geral, apresentados por especialistas ligadas às mesmas instituições que tinham estado representadas naquela conferência. Foram contempladas as coleções de escultura, tratadas por Claudia Valeri (Museus Vaticano), as coleções de artes decorativas e industriais abordadas por Isabel Rodríguez Marco (Museu Nacional de Artes Decorativas, Madrid), as coleções pré-históricas analisadas por Szilvia Fábián (Museu Nacional da Hungria) e as coleções de artes gráficas, que constituem o foco de Isabel Ortega (Biblioteca Nacional de Espanha). Seguindo idêntica metodologia, as autoras identificam os princípios defendidos em 1934 e estabelecem o seu desenvolvimento ao longo dos tempos. É no domínio das artes gráficas que se evidenciam as maiores divergências, fruto da evolução dos sistemas de catalogação e do conhecimento sobre a conservação do papel.

A terceira parte encerra com a visita a Toledo, organizada no âmbito da conferência do IMO, tratada por Santiago Palomero e de Jesús Carrobles Santos. Na altura, a cidade apresentava-se como um exemplo a seguir no domínio do turismo cultural, devido ao modelo de gestão do património implementado pelas elites toledanas na sequência das celebrações do III Centenário de El Geco. 0 Museu Arqueológico Provincial, em particular, depois de um passado atribulado, tinha ressurgido noutro edifício como uma referência internacional, onde pela primeira vez as coleções puderam ser dignamente exibidas. 0 estudo destaca a singular reabilitação e divulgação cultural de que Toledo beneficiou nas primeiras décadas do século XX, encerrando com referência à onda de destruição que se abateu sobre a cidade, durante a Guerra Civil, causando danos irremediáveis em boa parte dos acervos do Museu Arqueológico.

Em suma, podemos afirmar que a publicação coordenada por Alicia Herrero e Carmen Sanz, decorrente da Nova Conferência Internacional de Museus (Madrid, 2016), como lhe chamou José Luzón Nogué, veio preencher uma lacuna no conhecimento sobre a conferência que no âmbito da IMO teve lugar em Madrid, em 1934, dando-lhe merecida visibilidade no domínio da história da museologia e da museografia, ao mesmo tempo que se homenagearam condignamente os seus protagonistas. Fiel aos temas então tratados e ao modelo de organização seguido nos volumes das atas então publicados, a obra agora em apreço alcançou, em nosso entender, com grande 
pertinência e atualidade os objetivos que se propôs alcançar, apresentando um conjunto de textos bem encadeados que proporcionam um conhecimento integrado das problemáticas.

Através de uma abordagem retrospetiva é amplamente analisado o evento que decorreu nos anos de 1930, sob o olhar crítico de destacados especialistas em cada uma das matérias tratadas, que lhe reconheceram elevado pioneirismo em inúmeros assuntos. Simultaneamente, desenvolve-se uma perspetiva contemporânea, atualizada, sobre as mesmas matérias, beneficiária das múltiplas experiências vivenciadas nas décadas que se seguiram à conferência da IMO, permitindo a partilha de conhecimento sobre os grandes temas hoje em discussão no domínio dos museus. Constituiuse, assim, um importante repositório de saber, apto a apontar novos e pertinentes caminhos de investigação.

Notas

1 O volume não contempla as coleções etnográficas e de arte popular, nem as coleções de moedas e medalhas, embora tenham sido incluídas no programa da conferência. 